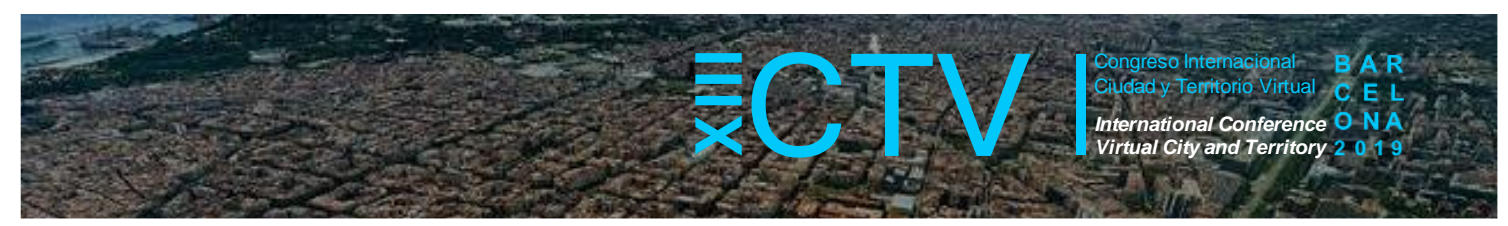

\title{
EL DERECHO A LA CIUDAD COMO NUEVO DERECHO HUMANO EMERGENTE
}

\author{
Zaragoza-Martí, María Francisca ${ }^{1 *}$
}

Remisión inicial: 2019-05-31; Remisión definitiva: 2019-09-24; Publicación: 2019-12-21

Citación: Zaragoza-Martí, M. F. (2019). El derecho a la ciudad como nuevo derecho humano emergente. In XIII CTV 2019 Proceedings: XIII International Conference on Virtual City and Territory: "Challenges and paradigms of the contemporary city": UPC, Barcelona, October 2-4, 2019. Barcelona: CPSV, 2019, p. 8492. E-ISSN 2604-6512. DOI http://dx.doi.org/10.5821/ctv.8492

\section{Resumen}

Actualmente, más del cincuenta por ciento de la población mundial vive en las urbes, configuradas éstas como lugar de reunión de una multiculturalidad moderna, innovadora y comprometida con su entorno, que no acepta seguir con el planeamiento urbanístico y de crecimiento desmesurado desarrollado durante las últimas décadas. Surgen así los movimientos sociales actuales que claman por un derecho a la ciudad como derecho humano emergente, basado en el valor de la solidaridad y la participación de todos, en la necesidad de compartir un espacio público en el que el ciudadano y la persona puedan encontrarse y construir comúnmente una ciudad que promueva y proteja los derechos fundamentales necesarios para el desarrollo de una vida adecuada. Desafortunadamente, los derechos humanos emergentes, sean ya nuevas reclamaciones o viejas pretensiones, no encuentran acomodo dentro de las clásicas generaciones de derechos humanos, situándose, por tanto, al margen de un sistema jurisdiccional vinculante a nivel internacional que exige obligaciones para los Estados, pero ante la necesidad de una regulación inminente tras la degradación a la que se encuentran hoy en día sometidos. La política burguesa de la élite mundial ha pervertido el sistema de derechos, pensados por y para todos, eliminando el acceso a los recursos e instituciones ciudadanas a través de las que se conforma comúnmente la ciudad. En atención a ello y a través de una metodología estrictamente jurídica, este estudio tiene por objetivo determinar el carácter jurídico del derecho a la ciudad, para lo que se abordará la dialéctica entre las generaciones de derechos y los nuevos derechos emergentes, analizando la ciudad y su derecho como un derecho básico y fundamental, especialmente a través de la teoría de la conectividad. A la vista de los resultados, existe únicamente un reconocimiento soft law del reclamado derecho a la ciudad, dado que no está recogido en textos normativos con fuerza jurídica vinculante, como sí lo estuvieron los derechos de primera y segunda generación, en los Pactos Internacionales de 1966. Sin embargo, a través de la conectividad de derechos es posible asegurar que el derecho a la ciudad posee los mismos caracteres definitorios que los derechos de la primera y segunda generación, por lo que puede y debe ser reconocido como derecho humano básico y transversal, donde se desarrolla e implementan muchos otros derechos fundamentales. A pesar de ello, su implementación no podrá lograrse sin prestar atención a las desigualdades existentes y sin una participación colectiva de todos los entes afectados. Por ello, es necesario seguir avanzando por la implementación de nuevos enfoques más participativos, integradores, innovadores y eficaces, desde la perspectiva glocal (local y global) que permita configurar la ciudad como espacio indispensable para el desarrollo vital del ser humano y de los derechos que lo caracterizan como persona, sobre los principios de equidad, justicia social, democracia y sostenibilidad, pudiendo encontrar reflejo en la normativa jurídica vigente.

\begin{abstract}
Currently, more than fifty percent of the world's population lives in the cities, configured as a meeting place for a modern, innovative and committed multiculturalism with its environment, which does not accept continuing urban planning and excessive growth developed during the last decades The current social movements that claim for a right to the city as an emerging human right, based on the value of solidarity and the participation of all, arise in the need to share a public space in which the citizen and the person can meet and commonly build a city that promotes and protects the fundamental rights necessary for the development of an adequate life. Unfortunately, emerging human rights, whether new claims or old claims, do not find accommodation within the classic generations of human rights, thus being outside a binding jurisdictional system at international level that demands obligations for States, but in view of the need for imminent regulation after the degradation to which they are subjected today. The bourgeois policy of the world elite
\end{abstract}

${ }^{1}$ Doctora en Derecho, Instituto Interuniversitario de Geografía, Departamento de Derecho Constitucional, Universidad de Alicante, https://orcid.org/0000-0003-3912-0395. * Correo de contacto: maría.zaragoza@ua.es 


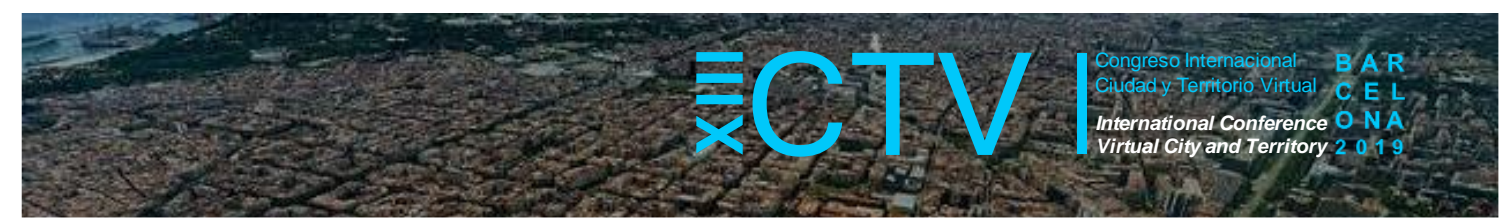

has perverted the system of rights, designed by and for all, eliminating access to citizen resources and institutions through which the city commonly forms. In response to this and through a strictly legal methodology, this study aims to determine the legal nature of the right to the city, for which the dialectic between the generations of rights and the new emerging rights will be addressed, analysing the city and its law as a basic and fundamental right, especially through the theory of connectivity. In view of the results, there is only a soft law recognition of the claimed right to the city, since it is not included in normative texts with binding legal force, as were the rights of first and second generation, in the International Covenants of 1966 . However, through the connectivity of rights it is possible to ensure that the right to the city has the same defining characteristics as the rights of the first and second generation, so it can and should be recognized as a basic and transversal human right, where many other fundamental rights are developed and implemented. Despite this, its implementation cannot be achieved without paying attention to existing inequalities and without collective participation of all affected entities. Therefore, it is necessary to continue advancing through the implementation of new, more participatory, integrative, innovative and effective approaches, from the glocal perspective (local and global) that allows the city to be configured as an indispensable space for the vital development of human beings and rights. that characterize him as a person, on the principles of equity, social justice, democracy and sustainability, being able to find reflection in current legal regulations.

Palabras Clave: derecho humano emergente; ciudad; perspectiva glocal; calidad de vida

Key words: emerging human right; city; ecosocial paradigm; quality of life

\section{Introducción}

Los derecho humanos, tanto conceptual como nominativamente, han sufrido una extensa evolución a lo largo de la historia reciente, puesto que cada una de las corrientes filosóficas que se ha encargado de su estudio los ha tratado de forma acorde a sus ideales, encontrando tanto posturas que parten del concepto natural e individual de los derechos humanos y, por tanto, originarios y anteriores al Estado, como aquellas otras que se apoyan más en tesis sociológicas a través de las que el derecho no puede sino existir en coordinación con la sociedad. Pero, al margen de esa multitud de conceptos, ideas o posiciones doctrinales 0 filosóficas primigenias, lo que sí queda claro es que los derechos del ser humano, originariamente, obtuvieron esta catalogación porque se configuraron como aquellos derechos surgidos de la naturaleza de los que aquel era el titular por el mero hecho de ser un ser humano, con independencia de su religión, origen o pensamiento.

La expresión más notoria de los Derechos Humanos se encuentra, sin duda, en el artículo 1 de la Declaración Universal de Derechos Humanos al mencionar que "todos los seres humanos nacen libres e iguales en dignidad y derechos, dotados como están de razón y conciencia, deben comportarse fraternalmente los unos con los otros", ya que Naciones Unidas define los derechos humanos como las condiciones de la existencia humana que permiten al ser humano desenvolverse y utilizar plenamente sus dotes de inteligencia y de conciencia, en orden a la satisfacción de las exigencias fundamentales que le impone su vida espiritual y natural. Es decir, que son los principios y las normas universalmente aceptadas que tienen que regir los actos de las personas, las comunidades y las instituciones si queremos que se preserve la dignidad humana y se fomente la justicia, el progreso y la paz que, además, se constituyen como obligaciones para los Estados en relación con su promoción y protección.

En consecuencia y como menciona Sánchez Sánchez (2005) el valor fundamental de los derechos humanos es la dignidad de la persona y la realidad social que proporciona la consistencia necesaria para que puedan ser reconocidos, respetados y promovidos en su conjunto, de forma indivisible e interdependiente, pudiéndose proyectar hacia un desarrollo perfectible. Idea que viene reforzada por la afirmación explícita de la Declaración de Viena de 1993, adoptada por la Conferencia Mundial de Derechos Humanos (Doc A/CONF.157/23 de 


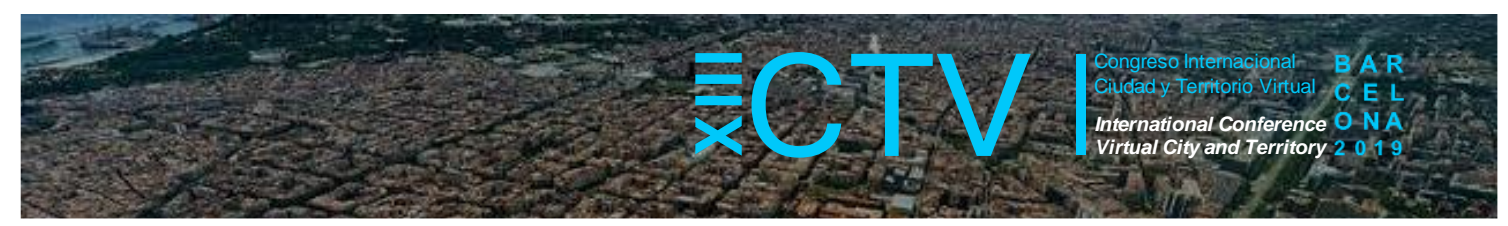

1993), según la cual dichos derechos son universales (es decir, corresponden a todos los seres humanos de igual forma), son indivisibles (lo que supone la imposibilidad de separar las distintas categorías de derechos, porque todos ellos son derechos necesarios, por lo que deben garantizarse en su totalidad) y son interdependientes (puesto que los derechos humanos son complementarios). Dícese, que el carácter universal de los derechos humanos y las libertades fundamentales no admite dudas, estableciendo para los Estados el deber, sean cuales sean sus sistemas políticos, económicos y culturales, de promover y proteger todos los derechos humanos y todas las libertades fundamentales.

Es esta última afirmación con la que hoy en día se conectan las reivindicaciones más recientes de los derechos sociales o derechos emergentes, en general, y del derecho a la ciudad en particular, puesto que la mitad de la población mundial vive hoy en las ciudades. Como menciona Velasco Arroyo (1990) la relevancia actual de los derechos humanos y su papel central dentro de la filosofía práctica vendría dada por su configuración como línea transversal que cruza las dimensiones de lo ético, lo jurídico y lo político, dado que poseen un sustrato que los configura como aspiraciones morales comunes a la Humanidad entera, conformando así el único código mínimo de una ética universalmente aceptada, aunque también poseen una indudable vocación y virtualidad política, porque la garantía de los mismos ha llegado a convertirse en una especie de suprema instancia legitimadora del ejercicio de cualquier poder político. Igualmente lo afirma, de forma rotunda, Loperena Rota (1999) al establecer que los derechos humanos se han convertido en el parámetro clave del desarrollo civilizatorio, puesto que son un elenco de principios ético-políticos que debidamente juridificados se convierten en el basamento de cualquier sistema jurídico.

En atención a ello y como nos recuerda Alvarado Alegría (2016), la ciudad es una institución, un objeto humano producto de la urbanización que, dependiendo de cómo es construida, planeada y gestionada, puede ser un elemento de vital importancia para garantizar los derechos humanos o, por el contrario, vulnerarlos, de ahí que la acción pública de las ciudades se haya ido encaminando hacia las reivindicaciones de su papel y, en particular, de su gobierno y de sus tribunales, como administraciones protectoras de los derechos fundamentales.

Originariamente, la ciudad fue concebida como un espacio de reunión, de fraternidad, de relación, de lo social, que permitía entender el término 'habitar' (Molano Camargo, 2016) como una actividad social que confería a los ciudadanos identidad urbana y, por ende, los habilitaba para la participación política. La ciudad era una obra que unificaba lenguajes, códigos y tejidos sociales comunes (Costes, 2011), magnificaba las relaciones del hombre con su entorno, con el territorio donde habitaba, con la sociedad y con el poder, dando forma a las relaciones político-estatales necesarias para salvaguardar los derechos de los ciudadanos. El mundo de la ciudad, como lo menciona Besse (2005), era concebida como la articulación o la unión de una forma urbana, un territorio físico (urbs) y las asociaciones políticas de la comunidad de ciudadanos que en ella viven (civitas), donde la ciudad es una ciudad y al mismo tiempo un espacio construido (también percibido y vivido, según Lefebvre), una organización política y un espacio organizado, una idea y una realidad espacial.

Desafortunadamente, como menciona Harvey (2008), la calidad de la vida urbana se ha convertido en una mercancía, como la ciudad misma, en un mundo en el que el consumismo, el turismo, las industrias culturales y las basadas en el conocimiento se han convertido en aspectos esenciales de la economía política urbana, de forma que el derecho a la ciudad se 


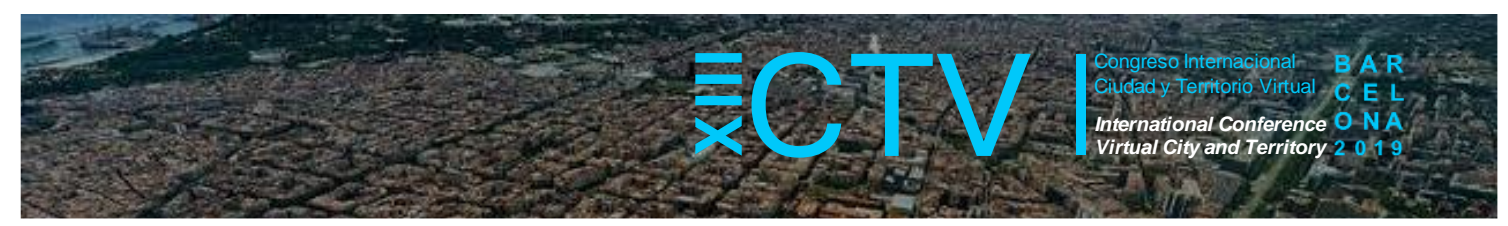

encuentra demasiado restringido sólo a una reducida élite política y económica que se halla en condiciones, cada vez más, de conformar las ciudades de acuerdo a sus propios deseos. Además, cuando en la ciudad se privilegia el valor del cambio y eso se expresa en los contenidos de las políticas urbanas, éstas dejan de ser concebidas como políticas sociales (Ziccardi, 2016).

Todo este proceso de declive urbano ya lo anunciaba Henry Lefebvre, en 1968, con los movimientos migratorios de la clase obrera hacia zonas no urbanas, la politización elitista de las urbes y la reconversión de las mismas en espacios segmentados y divorciados del espíritu social y cooperativo del que emergió la civis. Más reivindicativamente lo expresa Zárate (2014) al afirmar que la concentración de poder económico y político, ciertamente agravado a partir de la dogmática y reiterada aplicación de las salvajes políticas neoliberales surgidas del Consenso de Washington, es el fenómeno de explotación, despojo, desigualdad, exclusión y discriminación cuyas dimensiones espaciales son claramente visibles: ciudades duales, de lujo y miseria, vecinas y amuralladas; miles de inmuebles vacíos y miles de personas sin un lugar decente donde vivir; tierra sin campesinos y sometidas a agro-negocios y concentración en pocas manos de los bienes comunes y la riqueza colectivamente creada.

Por ello no es de extrañar, nos dice Subirats (2014), que aparezcan, por un lado, las condiciones propicias para la aparición de movimientos capaces de impulsar el cambio urbano y social y, por otro, construir una nueva arquitectura institucional que promueva experiencias puntuales de innovación social para la creación o recuperación de espacios públicos degradados, donde se desarrollen acciones colectivas que permitan fortalecer la identidad local, la vida comunitaria y avanzar en la construcción de una cultura democrática. Y ello no necesariamente debe realizarse a costa del paisaje y la cultura del territorio no urbano, pues ambas reivindicaciones van de la mano, ya que todo forma parte del mismo derecho a la vida y a la calidad de la misma en condiciones de igualdad. Hay que tener claro que, sin un espacio común, territorialmente estable y sostenible que promueva las interacciones sociales que crean y dan forma a las sociedades democráticas, será impensable ejercer el derecho a la ciudad como uno de los derechos básicos no ya sólo de la persona, sino también del ciudadano. Un ciudadano con derecho a participar socialmente, a interrelacionarse, a crear lazos y nexos de unión que fortalezcan el tejido de una sociedad avanzada democráticamente, la cual debe promover, proteger y fomentar los derechos humanos de los que todos somos titulares.

Desafortunadamente, el desarrollo urbano excesivo, el enriquecimiento constante de aquellos que negocian con los recursos de todos y la inactividad de los estados, incapaces de proteger y garantizar los bienes de titularidad pública, conlleva la necesidad de volver al pasado, de recordar el binomio humanidad-naturaleza en adecuada simbiosis, fruto del que surgió el desarrollo social (Zaragoza-Martí, 2019). Especialmente, para derechos como el que aquí se estudia, dado que como le ocurre al derecho humano al agua, el derecho a la ciudad, tan básico como el primero para el desarrollo de la personalidad y la vida en calidad, se ubica dentro de los derechos de solidaridad, derechos históricamente degradados por no encontrar su reflejo normativo en instrumentos de hard law y que a pesar de estar constantemente en las actuales agendas políticas, como los conflictos geopolíticos del futuro, no existe acción unitaria estatal que reconozca, garantice y promueva su carácter humano y básico.

Como decía Zárate (2014), la ciudad-negocio para unos pocos vale más que la ciudad-derecho para todos. De ahí que sea tan necesario abogar por cambio de paradigma reivindicando la 


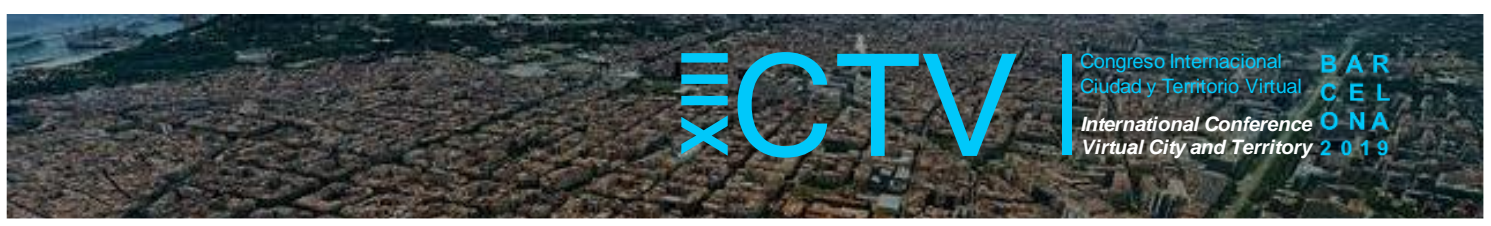

ciudad como un derecho de toda persona a pertenecer, disfrutar, usar, construir y desarrollar la misma de forma conjunta, porque como bien remarca Buckingham (2011) no existe un prototipo humano homogéneo singular que pueda servir de base para definir cuáles son las necesidades de la gente y, a su vez, cómo deben satisfacerse a través de la articulación de sus respectivos derechos, sino que el proceso de definir la particular necesidad humana de tener un nivel de vida adecuado debe considerar una multitud de identidades diferentes y cruzadas que habitan en el contexto particular y cómo su identidad social moldea las formas en que viven y crean el entorno.

En consecuencia, a través de una metodología estrictamente jurídica, se realizará un breve recorrido por las generaciones de derechos existentes y su confrontación con los nuevos derechos, con el fin de determinar el carácter jurídico del derecho a la ciudad y su posible catalogación como derecho humano a través de la teoría de la conectividad de derechos, pudiendo así otorgarle eficacia jurídica por conexión con otros derechos humanos básicos que ya cuentan con ello.

\section{Las generaciones de derechos y el derecho a la ciudad: en busca de su categorización como derecho humano}

La ciencia jurídica se caracteriza por su constante evolución en contacto con la realidad de la cual se sirve para su constitución, por lo que cada época histórica implementa sus huellas en el cuerpo jurídico del momento, si bien con la constante de la protección de los derechos de los individuos en diferentes niveles según el grado de desarrollo de la sociedad en cada tiempo. Por ello y partiendo de la afirmación que los derechos y las libertades constituyen el fundamento auténtico del Estado de Derecho, la mutación histórica de los derechos ha determinado la aparición de las denominadas 'generaciones de derechos' (Pérez Luño, 1991).

Cierto es que la categorización de los derechos en diferentes generaciones no es del todo compartida por la generalidad de la doctrina, por lo que creemos que clasificar los derechos de esta manera no quiere decir necesariamente que las generaciones posteriores surjan para eliminar las anteriores, sino que se produce un efecto de retroalimentación: las nuevas generaciones de derechos son consecuencia de la evolución y la readaptación social propia de las sociedades democráticamente avanzadas, más cuando los derechos surgen de las reclamaciones que en cada época se exigen, con distinto fundamento, pero sin que necesariamente impliquen distinción radical con lo anterior, pues en ocasiones desarrollan lo ya existente en otros aspectos no previstos con el objetivo de cubrir necesidades patentes no originadas previamente.

\subsection{Breve recorrido por las generaciones de derechos}

Se puede situar el origen de los derechos humanos en plena revolución burguesa, fruto de la lucha contra el abuso de poder por parte de las autoridades y auspiciada por los principios que defendía la Déclaration des Droits de l'Homme et du Citoyen de 1789: libertad, igualdad y fraternidad. Surge así la Primera Generación de Derechos, la de los derechos civiles y políticos cuya característica fundamental es que imponen al Estado el deber de respetar los derechos y las libertades de las personas. Como señala Alzamora Valdez (1977), son los derechos llamados 'libertades', porque se proclamaron para limitar las competencias o las atribuciones del Estado instituyéndose como garantías a la libertad. Entre las características que definen los 


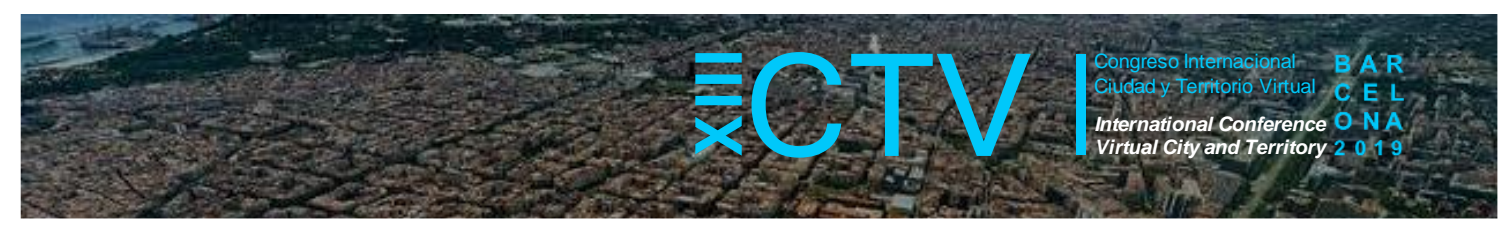

rasgos propios de los derechos de esta primera categoría se pueden señalar que son derechos absolutos, inmediatos y justiciables orientados a impedir intromisiones injustificadas en la persona como ser moral y a permitir la formación autónoma de decisiones (Pizorusso, 2002).

Más tarde, con la Revolución Industrial de 1917 se impondrá la necesidad de ampliar el catálogo de derechos como consecuencia de las luchas entre las clases sociales, especialmente debido a las reivindicaciones de los derechos de los campesinos, los obreros y los intelectuales. En consecuencia, el individuo pasa a ser considerado parte de la comunidad, surgiendo así la Segunda Generación de Derechos, la de los derechos económicos, sociales y culturales, caracterizados por la transformación del Estado liberal de derecho en el Estado social de derecho, donde éste ya no sólo debe respetar los derechos y las libertades, sino también ejercer una función activa de prestación de servicios y satisfacción de las necesidades. El proletariado fue sin duda el protagonista indiscutible de la lucha por el reconocimiento de nuevos derechos, tal y como ya reclamaba Lefebvre en relación con el actual derecho a la ciudad. Estos derechos tienen como objetivo la justicia social y el bienestar común, fundamentados sobre el valor de la dignidad y desarrollados sobre el comportamiento positivo a favor de la ciudadanía, no ya sólo como individuos sino como individuos que conforman un grupo, un colectivo con derechos comunes. Son derechos con características de graduales, no justiciables y de acción positiva, pues la libertad esencial de la primera generación se convierte en una libertad positiva, dado que la obligación del Estado no es ya de mero resultado, sino que se ha convertido en una obligación positiva de comportamiento.

La Tercera Generación de Derechos es fruto de las consecuencias que dejó tras de sí la Guerra Fría, con el aumento considerable del número de países pobres y la supremacía exclusiva del sistema militar, político y económico bipolar implantado por la URSS y los EE.UU. Nacen así los derechos de solidaridad entre los diferentes pueblos afectados por conflictos supranacionales, generando la cooperación entre todos ellos para retomar los períodos de paz, crecimiento y prosperidad entre los Estados y sus ciudadanos, respetando su derecho como nación. A diferencia de las anteriores generaciones, si el titular de los derechos de la primera generación era el ser humano aislado y los protagonistas de los derechos de la segunda generación eran los seres humanos en grupo, las nuevas circunstancias actuales exigen que la titularidad de los derechos de tercera generación corresponda, solidaria y universalmente, a todos los seres humanos, porque el individuo y los grupos resultan ya insuficientes para responder a las agresiones actuales que afectan a toda la Humanidad. Como consecuencia de ello, el valor sobre el que se sustentan estos derechos no es otro que el de la fraternidad, convertida ahora en solidaridad internacional entre los pueblos, puesto que a través de ella se practican otros valores tan necesarios como el de la dignidad y la libertad, elementos constitutivos de las precedentes generaciones de derechos.

Se observa, por tanto, una interconexión entre las diversas generaciones de derechos, ya que, aunque tengan su base en tres valores diferentes, éstos se mezclan e interrelacionan en sus actuaciones. Cabe recordar, como menciona Vasak (1990), igualmente aplicable al derecho a la ciudad, que los últimos derechos (los de la tercera generación) no pueden ser realizados más que gracias a la puesta en marcha de los otros derechos humanos que son, de alguna manera, sus elementos constitutivos. Es decir, que se ha producido una transformación evolutiva desde posiciones individualistas y comunitarias a universales, de tener derecho en y para sí, a derechos con los demás, ya que vivimos en un mundo globalizado donde la acción más pequeña en el lugar más remoto se siente y se percibe en la otra punta del mundo. Y ello 


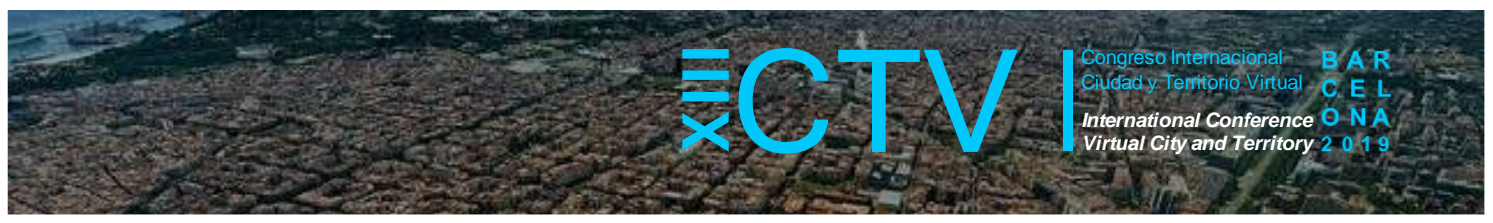

es especialmente importante desde el momento en que el ser humano ha sobrepasado los límites de crecimiento y ha empezado a poner en peligro su entorno de forma que afecta al modo en que desarrollamos nuestra vida y a la estructura y composición los derechos que configuran las sociedades.

\section{2 ¿Nuevas generaciones de derechos? El derecho a la ciudad como derecho humano}

Si partimos del hecho de reconocer que una concepción generacional de los derechos humanos implica reconocer que el catálogo de las libertades nunca será una obra cerrada y acabada, más, nos dice Pérez Luño (1991) cuando una sociedad libre y democrática debe mostrarse sensible y abierta a la aparición de nuevas necesidades que fundamenten nuevos derechos, es lógico que encontremos nuevos actores y nuevos movimientos sociales no reconocidos, pues especialmente la tecnología ha redimensionado las relaciones del hombre con los demás hombres, las relaciones entre el hombre y la naturaleza, así como las relaciones del ser humano con su contexto o marco de convivencia.

A pesar que dogmáticamente, como hemos visto, los derechos se encuentran divididos en tres generaciones y sin entrar en las discusiones sobre si con ellas surgen nuevos derechos 0 simplemente renovaciones de los anteriores, entendemos que cada una de las nuevas generaciones de derechos (si aceptamos este término) surge como consecuencia de la evolución de las anteriores, según las demandas y las situaciones concretas que se dan en cada momento, en correlación con la evolución del sistema político de cada Estado. En consecuencia, hoy se habla de Derechos Emergentes en respuesta a la evolución natural del Estado, el cual genera nuevas necesidades y, por tanto, nuevos métodos de satisfacción de las mismas. De esta forma, como especifica Saura i Estepà (2008) los derechos emergentes serían un conjunto de derechos que, por un lado, emergen tras haber quedado sumergidos en el olvido por la indiferencia de los Estados y del sistema internacional y, por otro, son también aquellos derechos que surgen de la rápida y constante evolución de las sociedades globalizadas.

Es decir, que tanto podrían ser meros recordatorios de otros derechos anteriores aún no jurídicamente reconocidos o que carezcan de eficacia jurídica, como pasa con los derechos de la tercera generación, como también el reclamo de derechos de nuevos colectivos no anteriormente previstos, porque si bien los derechos son universales e iguales para todos, no así son iguales los titulares que los reciben. Lo mismo ha ocurrido con el derecho a la ciudad, que, si bien debiera ser universal, desgraciadamente la comunidad internacional sólo se ha hecho eco de ello cuando han aparecido reivindicaciones que sobre el mismo han surgido de las situaciones de necesidad aparecidas actualmente. Ello explica la utilización del término 'aparición de nuevos derechos', ya que éstos nacen o aparecen cuando se dan situaciones de necesidad en las que se requiere el refuerzo de los valores universales del hombre y una acción colectiva para su subsanación, lo cual no le resta un ápice a su carácter universal, porque así lo son con independencia del momento o lugar en el que surjan o se encuentren los titulares que los reclaman.

En atención a ello, queda claro que el valor esencial de los derechos emergentes es el desarrollo internacional de la dignidad humana, valor esencial de todos los derechos humanos en atención al dinamismo propio de la sociedad internacional contemporánea, especialmente, 


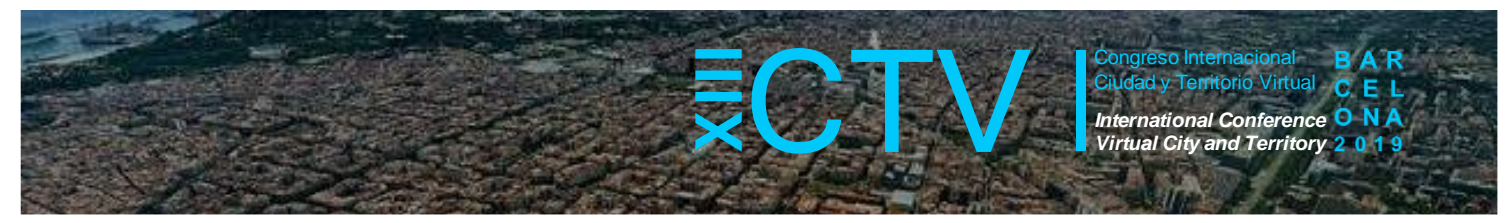

de una sociedad no gubernamental, de los activos movimientos sociales, a través de los cuales la ciudadanía manifiesta sus necesidades. Particularmente y en relación al derecho que aquí nos ocupa, este resurgimiento de la ciudad se debe especialmente a la explosión de nuevas luchas urbanas contra las expresiones espaciales del dominio del capital financiero, como la gentrificación o la degradación ambiental, pero también, el esfuerzo de los habitantes por lograr una mayor injerencia en la definición de las políticas urbanas (Molano Camargo, 2016). Especialmente porque, como recuerda Do Rio Caldeira, (2007), a pesar de contar con mayor crecimiento económico y mejores condiciones tecnológicas para diseñar la ciudad, los mecanismos de segregación espacial, el empobrecimiento de la experiencia urbana y la restricción de la participación y la democracia urbana, dificultan el acceso a la ciudad a la mayoría de sus habitantes. Pero es que ya no se trata sólo de una lucha anticapitalista (como promovía Harvey) o una lucha sectorial basada en género, raza o cultura (como pretendía Soja), sino que va más allá de toda particularidad pretendida, es una necesidad, una aspiración humana para construir y participar en una ciudad sostenible económica y medioambientalmente, donde se promueva, proteja y garantice el ejercicio común e igualitario de nuestras señas de identidad más básicas: los derechos del hombre.

Ya lo decía artísticamente Boja (2004) al mencionar que el urbanismo de la ciudad del siglo XXI debe optar por el collage, la mezcla, la diversidad de la poblaciones, actividades y usos plurales de los espacios, puesto que la ciudadanía es pluridimensional y requiere integraciones colectivas múltiples, bien para adherirse, participar o confrontarse. Igualmente, el proyecto de Carta de Derechos Humanos Emergentes define el derecho a la identidad colectiva en la ciudad (López Roa, 2012) como el derecho a una organización interna del espacio urbano que facilite la cohesión sociocultural de las comunidades, pues es necesario disfrutar, usar, mejorar, modificar ese gran espacio público que es la ciudad, donde todo ser humano encuentra las condiciones para su plena realización política, económica, social, cultural y ecológica. Así lo recoge, por ejemplo, la Declaración de Derechos Humanos Emergentes, pues en ella se refleja la necesidad de disponer del espacio ciudad como elemento esencial para el desarrollo y la mejora de la calidad de vida de las personas y el crecimiento democrático de los estados, pues sin una participación activa de los ciudadanos en la ciudad ésta se desvanece, pues sólo protegemos aquello en lo que nos vemos reflejados, aquello que tiene nuestra huella, aquello que hemos construido por y para todos, ese espacio que articula aspiraciones personales con realidades territoriales y sociales.

El derecho a la ciudad, así entendido, permite desarrollar y proteger muchos otros derechos básicos del hombre, promoviendo valores superiores del ordenamiento, como el derecho a la vivienda, la calidad del medio ambiente, el derecho al paisaje y a la fluviofelicidad, el derecho a la participación social y ciudadana, adaptabilidad a las tecnologías urbanísticas de calidad.... es decir, en palabras de la Carta Europea hacia la sostenibilidad, cada país debe velar por las ciudades como un todo orgánico, porque, además, ello, ayudará a la persecución de los Objetivos de Desarrollo Sostenible de Naciones Unidas. Según Jiménez Pacheco (2016) es sumamente necesario un espacio radical de vocación transformadora y carácter inalienable que se traduzca a la vida cotidiana, que no excluya al ser humano de su comunidad, que contribuya a la igualdad social, que alimente los instantes, los momentos de las personas comunes con el objeto de intensificar el rendimiento vital de lo cotidiano, un espacio apropiado para el ser humano donde una persona común logre su individualidad en una identidad colectiva. O como decía Park (1967) la ciudad es el intento más exitoso del ser humano de rehacer el mundo en el que vive de acuerdo con el deseo más íntimo de su corazón. 


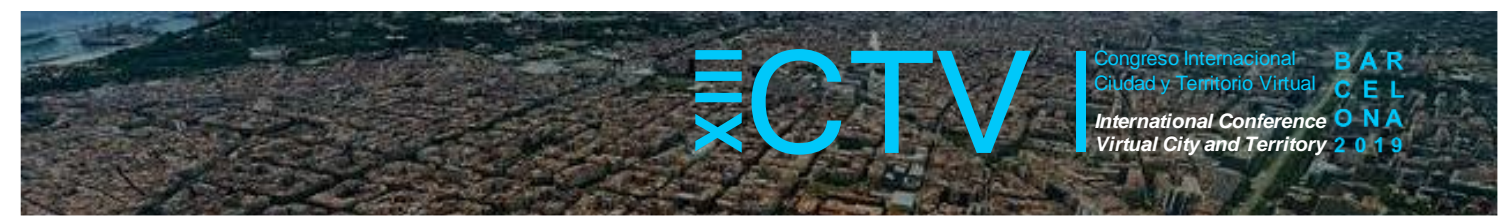

Pero, como sostiene la Plataforma Global por el Derecho a la Ciudad, el derecho a la ciudad no se limita a reivindicar los derechos humanos sin más sobre un territorio, sino que implica obligaciones de las autoridades y responsabilidades de la población en la gestión, producción y desarrollo de la ciudad, es un derecho dirigido a hacer posible que la ciudad sea de todas las personas que la habitan, transitan o visitan. Efectivamente, no se trata sólo de pensar que reivindicar el derecho a la ciudad es sólo una reivindicación de acceso a los centros de poder y a los espacios públicos que la ciudad ofrece para crear otros nuevos, quizás igualmente segregacionistas, sino que es igualmente, en palabras de Nicholls y Vermeulen (2012) la lucha por el derecho a la ciudad y la lucha por los derechos a través de la ciudad. Garantizado el derecho a la ciudad se garantizan igualmente otros elementos de la vida cotidiana y ciudadana igualmente básicos para el desarrollo humano, al margen de contribuir al ideario común, pues como dice Núñez (2009) el espacio del habitar son gestos, recorridos, cuerpo y memoria, símbolos y sentidos, contradicciones y conflictos entre deseos y necesidades, es un cambio en la práctica social que proponga y justifique la centralidad lúdica, poniendo la apropiación por encima de la dominación y reconstituyendo la unidad espacio-temporal de una nación.

Pero toda revolución necesita también revolucionar la vida cotidiana y la ciudad se vuelve un espacio estratégico para realizar esta tarea (Benítez, 2018), puesto que hoy, más que nunca, la complejidad que detenta la habitabilidad de las ciudades nos obliga a buscar nuevas prácticas de interacción social (Anduaga, 2017). El derecho a la ciudad no es una propuesta nueva, aunque sigue configurándose como derecho emergente debido a su falta de reconocimiento jurídico completo (Galiana Saura, 2017), quizás debido a la dificultad de concretar su contenido, ya que como venimos afirmando, el derecho a la ciudad es el continente de otros muchos derechos humanos del hombre. En este sentido, como exige Sugranyes (2010), el derecho a la ciudad no debería ser un derecho más, sino que se trataría del derecho a hacer cumplir los derechos ya formalmente suscritos por los Estados en tratados internacionales e instrumentalizados en el marco legal y normativo de los países. Es la propia Carta Mundial del Derecho a la Ciudad la que menciona que el derecho a la ciudad es interdependiente de todos los derechos humanos internacionalmente reconocidos y concebidos integralmente y, por lo tanto, incluye todos los derechos civiles, políticos, económicos, sociales, culturales y ambientales que ya están previstos en los tratados internacionales jurídicamente vinculantes. Es decir, que, por medio de la teoría de la conectividad de derechos, podemos afirmar que el derecho humano a la ciudad se encuentra regulado y reconocido como tal, aunque no tenga una regulación autónoma y propia (exactamente igual que lo reclamado para el derecho humano al agua y al saneamiento, ya que por un simple acto de olvido del pasado que lo consideró un elemento tan básico, esencial y transversal que no necesitaba ser reconocido, hoy, sin embargo, por no contar con un sistema eficazmente jurisdiccional de protección es el mayor conflicto geopolítico del siglo). Es más, esos derechos se relacionan con los recursos básicos que ofrece la ciudad: salud, vivienda, trabajo, educación, igualdad, participación social... recogidos como derechos fundamentales del hombre tanto en la Constitución Española como en el resto de normas internacionales aplicables. O de otra manera, tal y como lo mantiene la Association Internationale de Techniciens, Experts et Cherchers-AITEC (2003), el derecho a la ciudad significa ser capaz de contar con una vivienda confortable, un empleo que proporcione un modo de vida decente, ser capaz de establecer un hogar, vivir libre de agresiones policiales, pero también, de un modo más simple y específico, significa poder vivir en una ciudad que sea bella, funcional, saludable y respetuosa con el medio ambiente y con la configuración del ser humano según sus principios y derechos, añadiríamos. 


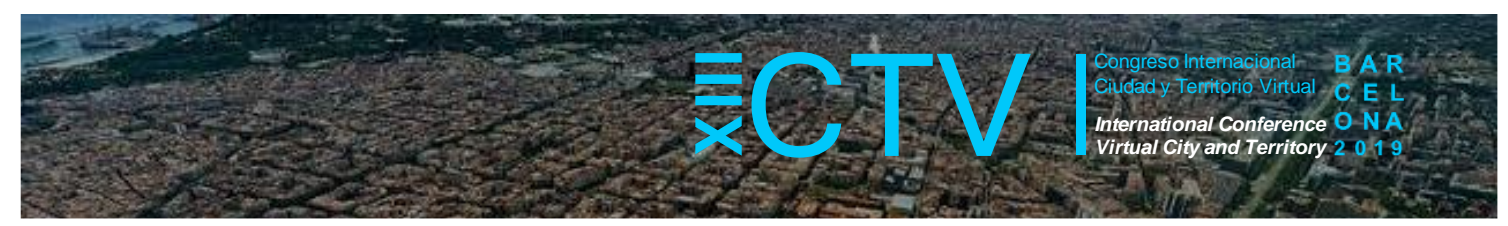

En definitiva, el derecho a la ciudad va más allá de la ciudad misma, se trata de un movimiento constante de ida y vuelta entre lo particular y lo universal, entre el pasado y el presente (Limonad \& Monte-Mor, 2012), porque la ciudad está en constante cambio, transformación evolución e interrelación con los elementos (sociales, ambientales, culturales, estructurales, económicos, personales, materiales, legales...) que le dan forma y color como el entorno adecuado donde el hombre da rienda suelta a sus emociones y convicciones para vivir en sociedad. De ahí que sea tan necesario vertebrar adecuadamente el movimiento social en busca de un reconocimiento jurídico vinculante que garantice y promueva este derecho sobre los principios de justicia social, equidad, democracia y sostenibilidad. Y ello es importante resaltarlo, porque como dice Smulovitz (2008) sólo cuando los movimientos son exitosos logran transformar los 'deseos' (wants) en 'derechos' (entitlements), consiguen que la demanda sea resuelta a través de procedimientos públicos y estandarizados, reduciendo el peso de las contingencias políticas en la resolución de los problemas y logran que el resultado sea imperativo. El derecho a la ciudad debe configurarse como la justificación que otorga fundamento a la pretensión humana de la ciudad como espacio público y del espacio público como elemento material y simbólico donde el resto de los derechos humanos, en conexidad, se pueden ejercer para reducir la desigualdad social y elevar la calidad de vida (Jiménez, 2006). 0 lo que es lo mismo, el derecho a la ciudad es hoy el concepto integrador de los derechos humanos y la base de la exigencia de estos derechos en un marco democrático, que requiere del reconocimiento, descripción y profundidad del sistema jurídico nacional, prima facie, a través de la conexidad de otros derechos fundamentales como la vida, la dignidad humana, la igualdad, la autodeterminación... pero con la solidez de un derecho fundamental que pronto puede configurar su propia autonomía jurisdiccional (Alvarado-Alegría, 2014).

\section{A modo de conclusión}

Nos recuerda el Institut de Dret Humans de Cataluña que los derechos humanos son el cimiento de las sociedades. Desafortunadamente, el paradigma de la dominación actual hace peligrar la sustentabilidad de los derechos del hombre, más cuando éstos no han sido definidos de manera permanente, pues responden a las necesidades cambiantes de la Humanidad. Los derechos humanos son el producto de luchas, de conquistas, de olvidos, pues como afirma Raffin (2008), un derecho sólo llega a ser verdad cuando se universaliza y se conquista de forma efectiva por todos los individuos en un momento histórico determinado y a la naturaleza de este momento histórico le corresponde la democratización de la tecnología como un nuevo norte en el camino hacia un concepto de ciudadanía que englobe a todos los seres humanos y garantice la calidad de vida. Y si el problema para reconocer las nuevas generaciones de derechos o los derechos en ellas contenidas se sustenta sobre el prisma de la exigibilidad jurídica, entonces deberíamos hacernos eco de las palabras de Pisarello (2010) cuando habla de la 'justiciabilidad por conexión', es decir, la tutela de los derechos por conexión con otros derechos fundamentales que, junto con el carácter indivisible e interdependiente propio de los derechos humanos, nos daría una respuesta afirmativa al interrogante sobre si el derecho a la ciudad es o no un derecho humano.

Acostumbrados a políticas depredadoras, la urbe actual despoja al hombre de sus derechos, sometidos únicamente al criterio capitalista de una minoría elitista, cuyas exigencias han llevado al borde del colapso nuestros estados, sus ciudades y a sus ciudadanos. Conflictos sociales y ambientales, crisis financieras y de gobernabilidad, insatisfacción ciudadana y violación de derechos fundamentales, todo ello expresiones de las luchas sociales 


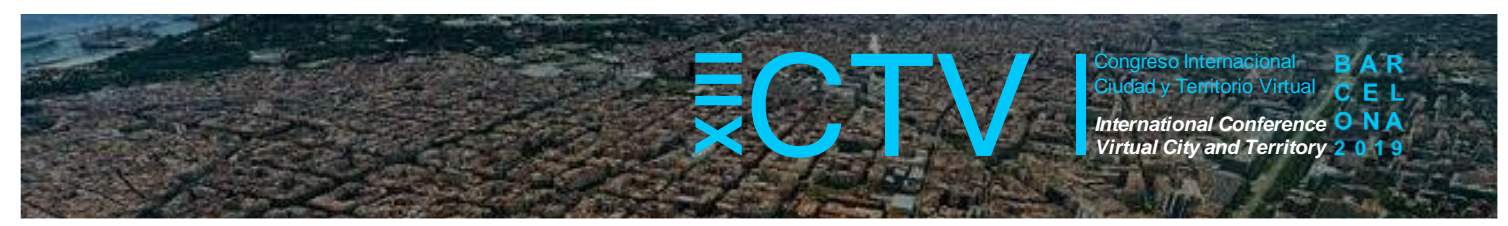

contemporáneas, que no sólo reclaman ya la tierra que por derecho les corresponde sino la necesidad de crear, disfrutar y compartir un espacio común donde las interrelaciones sociales y estatales se alineen para la salvaguarda de los derechos fundamentales, pues sin una ciudadanía comprometida, satisfecha y responsable no existe la ciudad como órgano de desarrollo social. El derecho a la ciudad, al espacio público como pilar fundamental de la urbe, requiere el reconocimiento de un marco jurídico vinculante a nivel internacional y no sólo reclamos civiles y sociales como los contenidos en la Carta Europea de Salvaguarda de los Derechos Humanos en la Ciudad, la Carta Mundial por el Derecho a la Ciudad o la Declaración Universal de Derechos Humanos Emergentes, entre otros, pues la conectividad de derechos es, desgraciadamente, sólo una teoría a expensas de la voluntad aplicativa de los Estados.

Agradecimientos: la autora quisiera agradecer al Instituto Interuniversitario de Geografía de la Universidad de Alicante su apoyo personal e institucional, así como su financiación constante. Igualmente, es de agradecer la acogida del área de derecho constitucional de la Facultad de Derecho de la misma universidad, donde esta autora desarrolla su actividad docente.

Conflicto de Intereses: la autora declara que no hay conflicto de intereses.

\section{Bibliografía}

AITEC (2003). Rapport d'Activités. Disponible en https://aitec.reseauipam.org/spip.php?article423

Alvarado-Alegría, N. (2014). El derecho a la ciudad como derecho humano emergente. Revista Ciencia@UaQro. Recuperable en: www.uaq.mx/investigacion/revista ciencia@uaq

Alvarado-Alegría, N. (mayo 2016). El derecho a la ciudad como derecho social en el estado constitucional. Trabajo presentado en el I Congreso de Filosofía del derecho para el mundo latino. Alicante, España.

Alzamora Valdez, M. (1977). Los Derechos Humanos y su protección. Lima, Perú: Eddili.

Anduaga, E. (2017). El derecho a la ciudad en la Constitución de la Ciudad de México. Una propuesta de interpretación. México: Instituto de Investigaciones Parlamentarias.

Benítez, J. (2018). El derecho a la ciudad como estructura de sentimiento: ¿nuevas formas preemergentes de significar la vivienda y el espacio urbano en la Ciudad Autónoma de Buenos Aires? Cuaderno Urbano-Espacio, Cultura y sociedad, 25 (25), 31-49.

Besse, J. M. (2005). Vue de ville et geographie au XVle siecle: concepts, demarches cognitive, functions. En F. Poussin (Ed.), Figures de la ville et construction des savoirs, Architecture, urbanisme, geographie (19-30), Paris: CNRS Editions.

Borja, J. (2004). Los derechos en la globalización y el derecho a la ciudad. Madrid, España: Fundación Alternativas.

Buckingham, S. (2011). Análisis del derecho a la ciudad desde una perspectiva de género. Revista de derechos humanos-Dfensor, 4, 6-12.

Costes, L. (2011). Del 'derecho a la ciudad' de Henri Lefebvre a la universalidad de la urbanización moderna. Urban, 2, 89-100. 


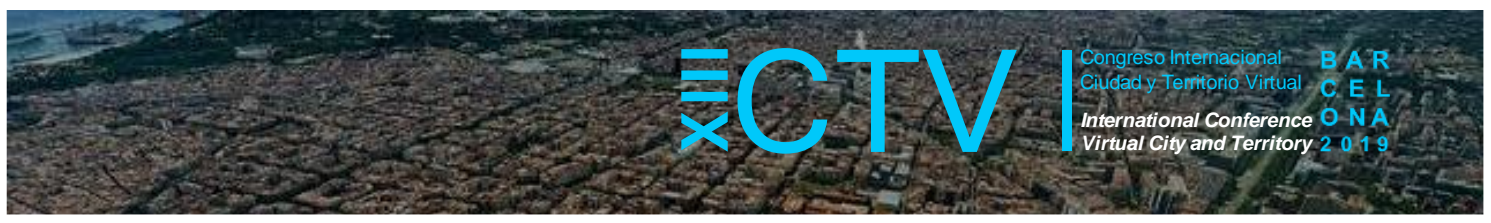

Do Rio Caldeira, T. (2007). Ciudad de muros. Bercelona, España: Gedisa.

Galiana Saura, A. (2017). La vivienda como objeto de estudio desde le derecho: la vivienda como derecho humano y la cátedra Unesco sobre vivienda. Hábitat y Sociedad, 10, 129-144.

Harvey, D. (2008). El derecho a la ciudad. New left Review, 53(4), 23-39.

Jiménez Pacheco (2016). Claves epistemológicas para descifrar el derecho a la ciudad de Henri Lefebvre. Estoa, 8(5), 21-28

Jiménez, M. (2006). Constitución y urbanismo. México: Unam-IIJ.

Limonad, E. \& Monte-Mor, R.L. (2012). Por el derecho a la ciudad, entre lo rural y lo urbano. Revista Electrónica de Geografía y Ciencias Sociales, 418(25). Recuperado de: http://www.ub.edu/geocrit/sn/sn-418/sn-418-25.htm

Loperena Rota, D. (1999). Los derechos al medio ambiente adecuado y su protección. Medio Ambiente \& Derecho-Revista Electrónica de Derecho Ambiental, 3. Recuperado de https://huespedes.cica.es/gimadus/

López Roa, J.C. (2012). El derecho al espacio público. Provincia, 27, 105-136.

Molano Camargo, F. (2016). El derecho a la ciudad: de Henri Lefebvre a los análisis sobre la ciudad capitalista contemporánea. Revista Folios, 44, 3-19.

Nicholls, W. \& Vermeulen, F. (2012). Right through the city: the urban basis of inmigrants rights struggles in Amsterdam and Paris. En P. E. Smith \& M. McQuarrie (Eds.). Remarking urban citizenship. Organizations, Instituttions and the right to the city (79-96). Amsterdam: New Brunswick Transaction Publishers.

Nuñez, A. (2009). De la alienación al derecho a la ciudad. Una lectura (posible) sobre Henri Lefebvre. Revista Theomai, 20. Recuperado de www.revista-theomai.unq.edu.ar

Park, R. (1967). On social Control and Collective Behavior. Chicago, EEUU: Chicago University Press.

Pérez Luño, A. (1991). Las generaciones de derechos humanos. Revista del Centro de Estudios Constitucionales, 10, 205.

Pisarello, G. (2010). La justiciabilidad d ellos derechos sociales en el sistema constitucional español. En VVAA. Los derechos sociales como derechos justiciables: potencialidades y límites (35-78), Albacete, España: Bomarzo.

Pizorusso, A. (2002). Las Generaciones de Derechos. Anuario de Derechos Humanos-Nueva Época, 3, 493-514.

Raffin, M. (2008). Pour une généalogie de la question de droits de l'homme. Revue Aspects, 1 , 119-126.

Sánchez Sánchez, R.M. (2005). Manual de Derechos Humanos y Democracia. Lima, Perú.

Saura i Estepà, J. (2008). Sobre el concepto y fundamento de los derechos humanos emergentes. En G. Ramírez (Coord.). Los Derechos Humanos en las sociedades contemporáneas (71-88), Méjico: Fondo Editorial de Nuevo León. 


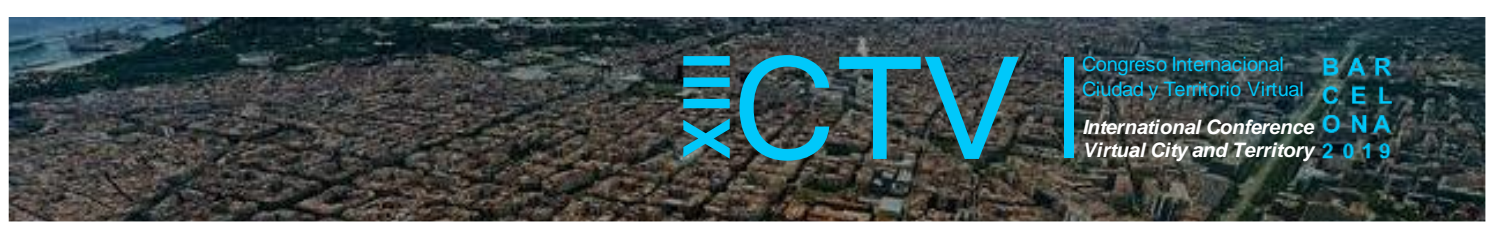

Smulovitz, C. (2008). Organizaciones que invocan derechos. Sociedad civil y representación en Argentina. Postdata, 13, 51-80.

Subirats, J. (febrero 2014). Innovación social y políticas urbanas. El debate sobre lo público en la ciudad. Ponencia presentada en el Seminario Internacional El derecho a la ciudad en América Latina. Visiones desde la política. Ciudad de México.

Sugranyes, A. (2010). El derecho a la Ciudad. Praxis de la utopía. Hábitat y Sociedad, 1, 71-79.

Vasak, K. (1990). Les différentes catégorie des Droits de l'homme. En A. Lapeyre, F. Tinguy \& K. Vasak (Eds.) Les dimensions universelles des drois de l'homme (297-316). Bruxelles: Bruylant.

Velasco Arroyo, J. C. (1990). Aproximación al concepto de los derechos humanos. Anuario de Derechos Humanos-Nueva Época, 7, 271.

Zaragoza-Martí, M. F. (2019). La exigibilidad de un cambio de paradigma ecosocial como herramienta de planificación y gestión hidrológica. En J. Melgarejo Moreno (Ed.). Congreso Nacional del Agua: Innovación y sostenibilidad (791-800). Alicante: Universidad de Alicante.

Zárate, M. L. (2014). El derecho a la ciudad: luchas urbanas por el buen vivir. En VVAA. Derecho a la ciudad y al territorio: una reflexión urgente (5-19). Medellín, Colombia: De la Región.

Ziccardi, A. (2016). El derecho a la ciudad. Megafón-La batalla de las Ideas, 9(1), 1-3. 